\title{
ВАИЯНИЕ ВНЕШНЕЙ ТОРГОВАИ И ПРЯМЫХ ИНОСТРАННЫХ ИНВЕСТИЦИЙ НА ЭКОНОМИЧЕСКИЙ РОСТ СТРАНЫ (НА ПРИМЕРЕ СТРАН СНГ)
}

\begin{abstract}
Аннотауия. Предмет. В статье рассматриваются вопросы влияния внешней торговли и прямых иностранных инвестиций на экономический рост страны. Џель работы. Џелью данной работы является выявление механизмов влияния экспорта, импорта и ПИИ на экономический рост, а также расчет коэффиииентов влияния на примере стран СНГ. Методология проведения работы. Выявление механизмов влияния экспорта, импорта и ПИИ на экономический рост достигалось в итоге сопоставления анализов разных авто-

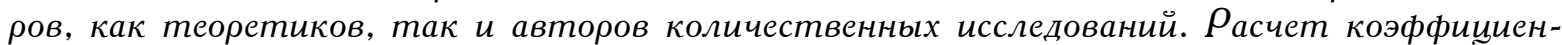
тов влияния данных переменных на ВВП страны на примере стран СНГ проводился методом наименьших квадратов, использовались панельные данные этих стран. Результаты работы. В результате проведенной работы представлены регрессионные модели влияния экспорта, импорта и ПИИ на экономический рост стран СНГ в трех разновидностях: 1. Регрессионная модель влияния экспорта, импорта и ПИИ на экономический рост стран СНГ без учета каких-либо других факторов. 2. Регрессионная модель влияния экспорта, импорта и ПИИ на экономический рост стран СНГ с учетом эффектов постоянных переменных. 3. Регрессионная модель влияния экспорта, импорта и ПИИ на экономический рост стран СНГ с учетом эффектов случайных переменных. Выводы. $B$ итоге регрессионного анализа нами выявлены следующие коэффищиенты влияния: рост экспорта на 1 \% спровоцировал рост ВВП на 0,97\%, увеличение импорта на 1 \% привело к увеличению ВВП на 0,269\%, а увеличение ПИИ на $1 \%$ сопровождалось увели-

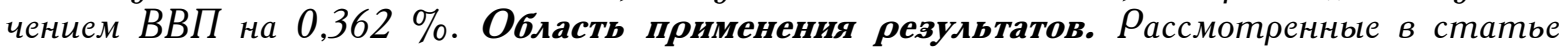
механизмы влияния внешних факторов на экономический рост могут быть полезны для дальнейших исследований на эту тему, а также для авторов, обучающих по данным программам. Выявленные коэффиииенты влияния могут быть полезны правительствам стран СНГ при разработке внешней экономической политики.
\end{abstract}

Ключевые слова: экономический рост, экспорт, импорт, прямые иностранные инвестиции, стимулирование экспорта, импортозамещение.

SARGSYAN LILIT NORAYROVNA

Candidate of Economic Sciences, Research Associate of the Institute of Economics named after M. Kotanyan of the National Academy of Sciences of the Republic of Armenia, e-mail: sarg.lilit@yahoo.com

\section{THE IMPACT OF INTERNATIONAL TRADE AND DIRECT FOREIGN INVESTMENTS ON THE ECONOMIC GROWTH OF THE COUNTRY (ON AN EXAMPLE OF THE CIS COUNTRIES)}

Abstract. Subject. The manuscript discusses the issues of impact of international trade and direct foreign investments on the economic growth in the country. The goal of the study. The goal of this study is finding the mechanisms of impact of export, import and FDI on the economic growth, as well as calculating the indices of impact on an example of the CIS countries. The methodology of completing the study. Finding the mechanisms of impact of export, import and FDA on the economic growth was achieved as a result of comparing analyses of different authors, both theoreticians, as well as authors of quantitative studies. The calculation of indices of impact of the data of variables on the GD $\rho$ of the country on an example of the CIS countries was performed using the method of the least squares using panel data of these countries. The results of the study. As a result of the study completed we are suggesting a regression model of 
ВЛИЯНИЕ ВНЕШНЕЙ ТОРГОВЛЕЙ И ПРЯМЫХ ИНОСТРАННЫХ ИНВЕСТИЦИЙ НА ЭКОНОМИЧЕСКИЙ РОСТ СТРАНЫ (НА ПРИМЕРЕ СТРАН СНГ)

impact of export, import and the FDI on the economic growth of the CIS countries in three variations: 1. a regression model of impact of export, import and the FDI on the economic growth of the CIS countries without taking into account any other factors, 2. a regression model of impact of export, import and the FDI on the economic growth of the CIS countries taking into account the effects of persistent variables, 3. a regression model of impact of export, import and the FDI on the economic growth of the CIS countries taking into account the effects of random variables. The conclusions. As a result of regression analysis, we have found the following indices of impact: the growth of export by $1 \%$ triggered the growth of the GDP by $0.97 \%$, the growth of import by $1 \%$ led to the growth of the GDP by $0.269 \%$, and the increase in the FDI by $1 \%$ was accompanied by the growth of the GDP by $0.362 \%$. The area of application of the results. The mechanisms of impact of external factors on the economic growth discussed in the manuscript may be useful for further research on these topics, as well as for authors of educational programs. The indices of impact found may be useful for governments of the CIS countries when developing the foreign economic policy.

Keywords: The economic growth, export, import, direct foreign investments, stimulating export, import substitution.

Введение. Экономический рост страны имеет ряд факторов, как внутренних, так и внешних. Экспорт, импорт и инвестиции являются одними из важнейших внешних факторов экономического роста. Экспорт - один из важнейших факторов экономического роста [30, с. 127], но этот фактор особенно важен для стран с малой экономикой, так как дает возможность предпринимателям с помощью эффекта масштаба производить еще большее количество продукции, что и приводит к экономическому росту [23, с. 25-28].

При обеспечении экономического роста правительства развивающихся стран рассматривают стимулирование экспорта как основную экономическую политику. По их мнению, с помощью экспорта страна получает иностранную валюту, необходимую для импорта, для решения проблем равновесия платежного баланса, для погашения внешнего долга и для остальных внешнеэкономических действий [31, с. 473-485; 26, с. 212].

Так как ресурсы страны ограничены, страна может производить и экспортировать не все товары. Таким образом, нужно понять, экспорт каких товаров может принести стране наибольшую пользу, и только на этой почве строить политику стимулирования экспорта. В основном экономические теории твердят, что наивысшей эффективности страна может достичь, стимулируя экспорт таких товаров, в которых у нее имеются совершенные, сравнительные или же конкурентные преимущества [25, с. 10-38; 23, с. 181-189]. Таким образом, страна может обеспечить наиболее эффективное распределение производственных ресурсов. Ряд экономистов считает, что в отличие от экспорта импорт страны сокращает экономический рост, но это далеко не так. Существует немало научных трудов, в которых твердят, что не только экспорт, но и импорт тоже может спровоцировать экономический рост, вот, например, импорт сырья, новейших технологий и оборудований, несомненно, приводит к экономическому росту [30, c. 95-105].

Что касается механизма влияния импорта на экономический рост, то, во-первых, нужно учесть, что благодаря импорту в страну вводятся товары, которые невозможно либо неэффективно производить внутри страны. Таким образом, ресурсы, внедренные в неэффективные отрасли страны, освобождаются и могут быть использованы в более эффективных отраслях [5, c. 71-102]. А что касается импорта новейших технологий, то можно констатировать тот факт, что их импорт, безусловно, приводит к экономическому росту. Ряд экономистов считает, что не только импорт новых технологий, но и импорт промежуточных товаров и полуфабрикатов тоже приводит к экономическому росту [29, с. 11]. Но иногда даже импорт бытовых продуктов тоже может спровоцировать экономический рост. Например, допустим, что страна производит те же бытовые товары, которые еще и импортируются. Это может привести к тому, что внутренние производители этих товаров будут вынуждены внедрить новые технологии в производство, чтобы конкурировать с импортированными товарами. Внедрение новых технологий и приводит к экономическому росту [6, с. 7].

Анализ литературы. До этого момента мы анализировали, каким образом экспорт и им- 
порт влияют на экономический рост. Но существует еще один немаловажный вопрос: экспорт и импорт в большей степени влияют на экономический рост в странах с низкими или высокими доходами? При выяснении этого вопроса в 2000 году Доллар и Краай провели анализ среди стран мира, разделяя их на 3 группы: страны с высокими доходами, которые после Второй мировой войны внедрили политику свободной торговли, развивающиеся страны, которые внедрили политику свободной торговли после 1980-х годов, и развивающиеся страны, которые не внедрили политику свободной торговли после 1980-х годов. В результате авторы показали, что в 1960-х годах темпы экономического роста были высоки в странах с высокими доходами, то есть в тех странах, которые в данный период уже внедрили политику свободной торговли. В 1970-х годах экономический рост был почти одинаковым во всех странах, а вот в 1980-1990-х годах в развивающихся странах, которые внедрили политику свободной торговли, темпы экономического роста были намного выше, чем в других развивающихся странах, которые пока что не усвоили свободу торговли, также выше, чем в странах с высоким уровнем доходов [20, с. 22-49].

Таким образом, мы можем констатировать факт, что свобода торговли позитивно влияет на экономический рост страны.

А какая связь существует между ПИИ и экономическим ростом? Этим вопросом задавались многие экономисты, но в данном случае нам особенно важно знать, как влияет ПИИ на экономический рост страны в том случае, когда страна осуществляет политику свободы торговли.

Как показывают результаты анализов разных авторов, в течение некоторого времени свобода торговли приводит к притоку ПИИ, а также позитивно влияет на экономический рост страны [32, с. 187-231]. Так, свобода торговли привлекает в страну иностранных инвесторов, этим и прибавляется спрос на качественную рабочую силу, что и приводит к увеличению объемов инвестиций в сфере образования. А это, естественно, влияет не только на развитие экономики, но и на благосостояние народа. Таким образом, нужно заметить, что влияние ПИИ на экономический рост намного выше в странах, которые внедрили политику свободы торговли. Работы некоторых экономистов показывают, что при увеличении удельного веса ПИИ в ВВП на $1 \%$ экономический рост прибавляется на $0,3 \%$ [18, с. 445-502]. Другой анализ показывает, что если в США доля основного капитала в ВВП увеличить на $1 \%$, то в следующем году ВВП увеличится на $0,12 \%$ [8, с. 232].

Как показывает мировой опыт, в странах с высоким экономическим ростом индекс инвестиции/ВВП находится в диапазоне $22-41,3 \%$ (22 \% - в Тайване, а 41,3 - в Сингапуре). Что касается стран с низким экономическим ростом, то данный индекс колеблется от 15,4 \% до $21,8 \%$, то есть в среднем в странах с высоким экономическим ростом данный индекс составляет $31 \%$, а в странах с низким экономическим ростом - почти что в двое ниже (19\%). Таким образом, можно сказать, что страны мира на капитальные инвестиции отводят около $20 \%$ своего ВВП [24, с. 62-78]. В Армении этот показатель намного ниже - около $12 \%$.

Некоторые экономисты уверены, что политика правительства может влиять на экономический рост как позитивно, так и негативно. Проблема в том, чтобы суметь сделать это влияние максимально эффективно [13, с. 8$]$.

Внешние экономические политики стран мира различаются между собой, тем не менее они содержат элементы либо свободной торговли, либо протекционизма. Этот подход актуален и сегодня, но, как показывает мировой опыт, в последнее время намечается тенденция склонности в большей степени к свободной торговле, нежели к протекционизму. Об этом говорит и сам факт того, что в последние десятилетия намечается тенденция сокращениия таможенных пошлин во всем мире.

Статистические данные твердят, что в течение 1980-2000-х годов ставки таможенных пошлин заметно сократились: в Африке они сократились с $33 \%$ до $20 \%$, в Азии - с $35 \%$ до $15 \%$, в Латинской Америке - с $30 \%$ до $13 \%$, а в Европе они сократились с $20 \%$ до $10 \%$. Противоположное явление наметилось только в странах Ближнего Востока, где ставки таможенных пошлин возросли от $13 \%$ до $16 \%$ [21, с. 8].

По прогнозам ВТО, уже в 2020 году закончится процесс создания зон свободной торговли по мировому масштабу [12, с. 62$]$. 
ВЛИЯНИЕ ВНЕШНЕЙ ТОРГОВЛЕЙ И ПРЯМЫХ ИНОСТРАННЫХ ИНВЕСТИЦИЙ НА ЭКОНОМИЧЕСКИЙ РОСТ СТРАНЫ (НА ПРИМЕРЕ СТРАН СНГ)

В своих трудах Дан Бен-Дейвид показал, что свобода торговли уменьшает разницу между доходами населения [15, с. 653-679].

Профессор Гарвардского университета предлагает иную модель экономического роста. По его мнению, государственная политика стран должна стимулировать развитие стратегических сфер экономики, интернационализацию местных корпораций, должна способствовать увеличению возможностей экспорта, в результате чего откроются новые рабочие места, увеличится приток валюты в государственный бюджет, а также увеличится объем ВВП [27, с. 260-264].

Ранние работы экспертов всемирного банка прогнозировали, что если бы развивающиеся страны вели политику свободной торговли, то уже в 2015 году они смогли бы сократить число бедного населения на 144 млн человек [17]. Но, как видим мы уже сейчас, не все развивающиеся страны внедрили политику свободы торговли, в результате чего и прогнозы экспертов остались невыполнимы.

А вот французский экономист М. Пебро считает, что свободная торговля более эффективна для развитых стран, а вот развивающиеся страны не могут полностью внедрить политику свободы торговли. Он считает, что если страна усвоит политику свободной торговли до того, как усвоит высокий темп развития, то это приведет к тому, что она рано или поздно станет колонией какого-то развитого государства. В связи с этим автор считает, что развивающиеся страны должны вести протекционистскую политику, чтобы достичь определенных темпов развития [9, гл. 1].

Как экономисты мировых масштабов, так и армянские экономисты приводят ряд аргументов за или против свободы торговли.

Экономист Т. Торосян считает очень важным проведение эффективной протекционистской политики. По его мнению, особенно важно применение протекционистских мер с точки зрения стимулирования экспорта, нежели замещения импорта. Он констатирует тот факт, что Армения - страна с малой экономикой и ограниченным внутренним спросом. Вот почему дальнейшее развитие страны зависит от внешнего спроса. По его мнению, для стимулирования экспорта нужно применить не только финансовые меры, но и налоговые и таможенные льготы $[11$, с. 4].

Другой экономист Э. Манасян считает, что правительство Армении должно внедрить протекционистские механизмы в тех сферах, где экономика Армении имеет сравнительные преимущества [6, с. 31]. Армянские сторонники свободной торговли смотрят на ситуацию с другого ракурса. Например, Н. Ерицян считает, что для развития стран с малой экономикой, таких как Армения, необходимо совместить производство конкурентоспособной продукции с открытой экономической политикой [3, с. 10-15]. А. Дарбинян считает, что открытая экономика - одна из важнейших факторов эффективного распределения ресурсов [2, с. 422]. А Р. Саринян считает, что свобода и самостоятельность фирм приводят к такому же развитию, как и экономическая свобода человека [10, с. 55]. А профессор А. Маркосян, анализируя сильные и слабые стороны экономики Армении, считает, что свободный режим внешней торговли Армении является привилегией для страны [7, с. 18-23]. А. Габриелян на анализе данных стран Южного Кавказа показал, что между экономическим ростом и свободой торговли существует долгосрочная стабильная связь [1, с. 38-41].

Методы. Целью данной статьи является выявление связи между экономическим ростом, экспортом, импортом и инвестициями. Для этого нами была анализирована основная литература на эту тему как с теоретической точки зрения, так и с точки зрения количественного анализа. Но для выявления влияния экспорта, импорта и инвестиций на экономический рост Армении и стран СНГ нами был проведен регрессионный анализ панельных данных 11 стран СНГ. Регрессионный анализ проведен с помощью пакета Stata V10.1, методом исследования является метод наименьших квадратов. При построении модели мы использовали годовые данные следующих переменных на период 2000-2016 годов: ВВП - в качестве зависимой переменной, а в качестве независимых переменных были использованы экспорт, импорт и чистый приток прямых иностранных инвестиций. Данные всех переменных рассчитаны в постоянных ценах 2000 года.

Число наблюдений составило 162. Основой для данных послужила база данных всемирного банка. Все данные представлены в виде натуральных логарифмов. 
Результат. Как уже отмечено выше, экономисты разделяются на две группы -сторонники свободной торговли и сторонники протекционизма, но каждая группа четко отмечает плюсы и минусы этих экономических направлений.

Однако отметим, что в каждой стране в определенный период времени протекционистская политика бывает вынужденной мерой для дальнейшего развитии страны и для того, чтобы новые стратегические сферы экономики смогли развиваться. Тем не менее, как показывает мировой опыт, крайне нежелательно применить таможенные ставки на импортирующее сырье, так как при производстве экспортных товаров часто употребляются импортное сырье и полуфабрикаты. Применение таможенных пошлин на импортное сырье, естественно, приводит к увеличению себестоимости производимых с их помощью товаров. А при производстве экспортированных товаров такой исход дел снижает конкурентоспособность экспортирующих товаров на внешних рынках.

Таким образом, можно отметить, что страны ведут протекционистскую политику тогда, когда хотят временно защитить местных производителей до того момента, как они встанут на ноги, а также когда хотят сократить дефицит текущего счета платежного баланса. С помощью данных мер правительство реализует политику импортозамещения.

Но на сегодняшний день все больше применяется иная индустриальная политика - политика стимулирования экспорта.

После Второй Мировой войны многие развивающиеся страны старались ускорить темпы экономического роста страны, ограничив импорт промышленной продукции страны и тем самим стимулируя местное промышленное производство. В этот период времени в данных странах ограничение импорта было необходимо, так как даже те новые развивающие сферы, которые имели сравнительные преимущества, не могли бы конкурировать с теми же сферами развитых стран. Вот почему в данный период данные страны были вынуждены применить такие меры предосторожности, а именно благодаря этим мерам они в дальнейшем развивались с ускоренными темпами экономического роста [4, с. 287].

Стратегия импортозамещения прошла более успешно в новых индустриальных странах Юго-Восточной Азии. Развитие этих стран прошло с ускоренными темпами как благодаря постепенному увеличению степени свободы торговли, так и при помощи одновременного применения стратегий стимулирования экспорта и замещения импорта.

В данных странах замещение импорта сопровождалось формированием промышленного комплекса благодаря аккумуляции внутреннего капитала. Это позволило странам создать диверсифицированную экономику и развить стратегические сферы экономики.

Нужно отметить тот факт, что те страны, которые сегодня уже считаются развитыми, в недалеком прошлом начали развиваться, применяя строгие экономические меры по замещению импорта и стимулированию экспорта. Например, в XIX веке США и Германия ввели огромные таможенные пошлины на импорт промышленных продуктов, а Япония проводила строгий контроль импорта до 1970-х годов. Тайвань начал развивать экономику страны на основе развития капиталоемких сфер экономики, совмещая это с политиками импортозамещения и стимулирования экспорта. В итоге в Тайване не только состоялся многофункциональный промышленный комплекс, но и структура экспорта стала более диверсифицированной $[5$, с. 122 $123]$.

Опыт последних десятилетий показывает, что самых высоких темпов экономического роста достигли страны, которые применили стратегию стимулирования экспорта. С этого ракурса особо больших успехов достигли страны Юго-Восточной Азии. А в их числе самые высокие темпы экономического роста наметилась в странах, в структуре экспорта которых большое место занимают технологические продукты [28, с. 23-30], в структуре импорта большое место занимают станки, сырье и полуфабрикаты [16, с. 337-370].

При анализе эмпирических исследований разных авторов нами было выявлено, что не только экспорт, но и импорт может стать основой для экономического роста, а не сократить его, как это в основном принято считать.

В данной статье мы изучим влияние экспорта и импорта на экономический рост в странах СНГ, чтобы понять тенденции развития каждой страны. Для этого мы проводили регрессионный анализ, построив модель с панельными данными 11 стран СНГ (Армения, Азербайджан, 
ВЛИЯНИЕ ВНЕШНЕЙ ТОРГОВЛЕЙ И ПРЯМЫХ ИНОСТРАННЫХ ИНВЕСТИЦИЙ НА ЭКОНОМИЧЕСКИЙ РОСТ СТРАНЫ (НА ПРИМЕРЕ СТРАН СНГ)

Белоруссия, Казахстан, Киргизия, Молдова, Россия, Таджикистан, Туркменистан, Украина, Узбекистан).

Результаты регрессионной модели представлены в таблице 1.

Таблицуа 1

Результаты регрессионной модели влияния экспорта, импорта и ПИИ на экономический рост стран СНГ

\begin{tabular}{|c|c|}
\hline Факторы, влияющце на ВВП & $\begin{array}{c}\text { Коэффициент } \\
\text { (стандартная ошибка) }\end{array}$ \\
\hline Экспорт & $\begin{array}{c}2,68 \\
(0,910)\end{array}$ \\
\hline Импорт & $\begin{array}{c}-0,91 \\
(0,145)\end{array}$ \\
\hline ПИИ & $\begin{array}{c}1,134 \\
(0,256)\end{array}$ \\
\hline Константа & $-9,34 \mathrm{e}+08$ \\
\hline
\end{tabular}

Из таблицы 1 видно, что Adj R-squared = 0,99. Это означает, что изменения ВВП в $99 \%$ можно объяснить изменением объема экспорта, импорта и ПИИ, то есть изначально мы выбрали для модели такие переменные, которые в большой степени объясняют изменение ВВП.

Итак, регрессионную модель можно представить в следующем виде:

$$
\text { GDP = -9.34e + 08 + 2,68 } \times \text { Exp - 0.91 } \times \operatorname{Imp}+1,134 \times \text { FDI }
$$

Таким образом, исходя из полученных нами коэффициентов, можно утверждать, что увеличение экспорта на $1 \%$ приводит к увеличению ВВП на $2,68 \%$, увеличение импорта на $1 \%$ спровоцирует увеличение ВВП на $0,91 \%$, а при увеличении ПИИ на $1 \%$, ВВП вырастет на $1,13 \%$

Но это еще не окончательный результат. Есть вероятность, что в течение исследуемого периода в каждой стране могут быть постоянные переменные, которые влияют на ВВП, но мы их не учитывали в модели (это могут быть любые характерные черты для каждой страны, например, число населения или уровень безработицы, или что-то другое). Для изучения всех этих случай мы примерим к модели метод эффектов постоянных переменных (fixed-effects method). Результаты приведены в таблице 2.

Таблица 2

Результаты полученной модели при применении метода эффектов постоянных переменных

\begin{tabular}{|c|c|}
\hline Факторы, влияющие на ВВП & $\begin{array}{c}\text { Коэффициент } \\
\text { (стандартная ошибка) }\end{array}$ \\
\hline Экспорт & 0,97 \\
& $(0,106)^{* *}$ \\
\hline Импорт & 0,269 \\
& $(0,953)^{* *}$ \\
\hline ПИИ & 0,362 \\
& $(0,125)^{* *}$ \\
\hline Константа & $1,71 \mathrm{e}+10$ \\
\hline \multicolumn{2}{|c}{ Adj R-squared $=0,9859$} \\
\hline
\end{tabular}

В данном случае регрессионную модель можно представить в следующем виде:

$$
\text { GDP }=1,71 \mathrm{e}+10+0,97^{\prime} \operatorname{Exp}+0,269^{\prime} \operatorname{Imp}+0,362^{\prime} \text { FDI }
$$

Но, как известно, не только константные переменные могут влиять на экономический рост, 
но и случайные переменные. Например, в каждой стране в течение исследуемого периода могли произойти случайные и непредвиденные изменения, которые негативно или позитивно смогли бы влиять на экономический рост. Для учета таких случаев нами был применен метод эффектов случайных переменных (random-effects method). Результаты показаны в таблице 3.

Таблица 3

Результаты полученной модели при применении метода эффектов случайных переменных

\begin{tabular}{|c|c|}
\hline Факторы, влияючце на ВВП & $\begin{array}{c}\text { Коэффициент } \\
\text { (стандартнал ошибка) }\end{array}$ \\
\hline Экспорт & 2,59 \\
& $(0,104)^{* *}$ \\
\hline \multirow{2}{*}{ Импорт } & $-0,88$ \\
& $(0,147)^{* *}$ \\
\hline ПиИ & 1,174 \\
& $(0,258)^{* *}$ \\
\hline Константа & $-2,87 \mathrm{e}+07$ \\
\hline \multicolumn{2}{|c|}{ Adj R-squared $=\mathbf{0 , 9 9 7 7}$} \\
\hline
\end{tabular}

В этом случае регрессионную модель можно представить в следующем виде:

$$
\text { GDP }=-\mathbf{2 , 8 7 e}+07+2,59^{\prime} \text { Exp - 0,88' Imp + 1,174' FDI }
$$

И после всего этого перед нами встает вопрос: какой из вышеперечисленных эффектов более значим для нашей модели? Чтобы ответить на данный вопрос, мы проверяем значимость эффектов с помощью теста Хаусмана. Тест Хаусмана показал, что значимость эффектов постоянных переменных намного выше, чем значимость эффектов случайных переменных. Таким образом, модель, которая наилучшим образом представляет зависимость ВВП от экспорта, импорта и ПИИ, является моделью с учетом эффектов постоянных переменных в следующем виде:

$$
\text { GDP }=1,71 \mathrm{e}+10+0,97^{\prime} \operatorname{Exp}+0,269^{\prime} \operatorname{Imp}+0,362^{\prime} \text { FDI }
$$

Выводы. В итоге анализа нами были выявлены наилучшие коэффициенты влияния экспорта, импорта и ПИИ на ВВП. Таким образом, можно утверждать то, что в исследуемом периоде в странах СНГ рост экспорта на $1 \%$ спровоцировал рост ВВП на $0,97 \%$, увеличение импорта на $1 \%$ привело к увеличению ВВП на $0,269 \%$, а увеличение ПИИ на $1 \%$ сопровождалось увеличением ВВП на $0,362 \%$.

Таким образом, во-первых, в нашем случае еще раз утвердился тот факт, что импорт может не только не сократить экономический рост, но и спровоцировать его увеличение. Это в большой степени зависит от структуры импорта.

Отметим, однако, что представленные коэффициенты являются средними показателями и могут не очень четко представить ситуацию в каждой отдельной стране. Например, коэффициент влияния импорта на экономический рост может быть выше в тех странах, в структуре импорта которых станки и сырье составляют не менее $15 \%$ (это среднее значение для стран СНГ на данный период). Такими странами являются Армения, Белоруссия, Россия, Казахстан, Киргизия, Молдова, Туркменистан, Украина и Узбекистан. А в остальных странах данный показатель может быть более низким, и даже отрицательным. Такими странами являются Азербайджан и Таджикистан.

К аналогичному выводу можно прийти при анализе влияния экспорта и ПИИ на экономический рост. В случае ПИИ можно учесть 2 фактора: насколько велик показатель ПИИ/ВВП и насколько высокое место занимает страна при расчете индекса ведения бизнеса. В тех странах, в которых эти 2 показатели выше, коэффициент влияния ПИИ на ВВП, соответственно, может быть выше. В случае экспорта коэффициент влияния может быть выше в странах, в которых экспорт более диверсифицирован.

В заключение можно сказать, что в Армении влияние экспорта, импорта и ПИИ может 
ВЛИЯНИЕ ВНЕШНЕЙ ТОРГОВЛЕЙ И ПРЯМЫХ ИНОСТРАННЫХ ИНВЕСТИЦИЙ НА ЭКОНОМИЧЕСКИЙ РОСТ СТРАНЫ (НА ПРИМЕРЕ СТРАН СНГ)

быть больше уже в полученных нами показателях в том случае, если:

- в структуре импорта страны увеличится объем новейших технологий, станков и сырья;

- в структуре экспорта 4 основные группы не будут привилегированы над остальными, как было в указанный период времени;

- правительство страны будет вести политику стимулирования экспорта, направляя инвестиции в те сферы экономики, которые обладают сравнительными или конкурентными преимуществами;

- правительство будет принимать меры для улучшения инвестиционного климата страны.

Область применения результатов. Рассмотренные в статье механизмы влияния внешних факторов на экономический рост могут быть полезны для дальнейших исследований на эту тему, а также для авторов, обучающих по данным программам. Выявленные коэффициенты влияния могут быть полезны правительствам стран СНГ при разработке внешней экономической политики.

Литература

1. Габриелян А. Связь между экономическим ростом и экономической свободой в Южном Кавказе, Айастан // Финансы и экономика. - № 10 (124), октябрь 2010 2. - С. 38-41 (на армянском).

2. Дарбинян А., Ордян А. Открытость экономики как основная предпосылка и средство эффективной международной экономической интеграции // Социально-экономические преобразовании за 10 лет независимости в Армении (Сборник научных статей). Ереван. - 2002. -422 с. (на армянском).

3. Ерииян Н. Без высоких амбиций невозможно добиться высоких результатов, Айастан: Финансы и экономика. № 13, декабрь 2009 г. - С. 10-15 (на армянском).

4. Кругман П., Обстфельд М., Международная экономика, издание 5-е, Питер 2004, 832 c.

5. Максимов А. . Экономика Тайваня: итоги и перспективы развития, М., 1991. - 208 с.

6. Манасян Э. Компоненты экономического роста Армении, Айастан // Финансы и экономика. - 2002. № 11. - С. 31 (на армянском).

7. Маркосян А. Армения на пути к рыночной экономике: достижения и предстоящие вопросы, Айастан // Финансы и экономика. - № 13, декабрь, 2009 г. - С. 18-23 (на армянском).

8. МкКинзи корп. Программа «Армения 2020», Ереван 2005 г. - С. 232.

9. Пебро М. Международные экономические, валютные и финансовые отномения, пер. с фр. 1994 г., $496 \mathrm{c}$.

10. Саринян Р. Современная армянская теория экономики, Ереван, 2003. - 232 c.

11. Торосян Т. Улучшение соотношения экспорта и импорта в Армении // Экономика. - № 1-3, Ереван, 1998 г. - С. 4 (на армянском).

12. Шумилов В. М. Международное экономическое право, книга 2, издание 2-е, перераб. и дополненное. - M. $-2001 .-288 \mathrm{c}$.

13. Arnold C. Harberger, Economic Policy and Economic Growth. San Francisco: International Center for Economic Growth, 1985, 48 p.

14. Balassa B. (1978). Exports and economic growth: further evidence, Journal of Development Economics. 5. P. 181-189.

15. Ben-David D. Equalizing Exchange: Trade Liberalization and Income Convergence, Quarterly Journal of Economices. Vol. 108. No. 3 (Aug., 1993). P. 653-679.

16. Chami Batista J. Latin American export specialization in resource-based products: implications for growth, The Developing Economies, XLII-3 (September 2004). P. 337-370.

17. Daryll E. Ray. Trade liberalization would shut down two-thirds of EU's grain and oilseed production, published in MidAmerica Farmer Grower. Vol. 21. No. 48. November 28. 2003. Article Number 173.

18. De Long J., Summers L. Equipment Investment and Economic Growth The Quarterly Journal of Economics. Vol. 106. No. 2 (May, 1991). P. 445-502.

19. Denison E. Accounting for United States Economic Growth 1929-1969. The Brookings Institution, Washington, D. C. 1974, 355 p.

20. Dollar D. and Kraay A., Trade, Growth and Poverty. The Economic Journal. Vol. 114. No. 493. Features (Feb., 2004). P. F22-F49.

21. Faini R. Trade liberalization in a globalizing world (Università di Roma Tor Vergata, CEPR, IZA and CSLA). Annual World Bank Conference on Development Economics, Washington, D. C. May 3-4, 2004,38 p.

22. Hagelstam J., Mercantillism Still Influences Practical Trade Policy at the End of the Twentieth Century, Journal of World Trade, 1991. P. 95-105.

23. Hausmann R. J. Hwang and D. Rodrik. 2006. "What You Export Matters». Working Paper. Center for International Development, Harvard University, $31 \mathrm{p}$.

24. Krugman P. The Myth of Asia's Miracle, Foreign Affairs, 1994. P. 62-78.

25. Krugman/Obstfeld, International Economics. 2003, Chapter 2: Labor Productivity and Comparative Advantage: The Riparian Model, 712 p.

26. Prebish R. The Economic Development of Latin America and its Principal Problems, United Nations Department of Economic Affairs, 1950. 247 p.

27. Reich R. The Work of Nations: Preparing Ourselves for 21 st Century Capitalism, New York: Vintage Books, 1991, 331 p. 
28. Rizal Damuri Y., Atje R., Gaduh Arya B. Integration and Trade Specialization in East Asia, CSIS working paper series, March 2006, 42 p.

29. Romer P. Endogenous technological change, Journal of Political Economy, 1990. P. 71-102.

30. Sangho K., Hyunjoon L. and Donghyun P. The Effect of Imports and Exports on Total Factor Productivity in Korea, 2002, 40 p.

31. Singer H. The Distribution of Trade between Investing and Borrowing Countries, American Economic Review, 1950. P. 473-485.

32. Wacziarg R. and K. Horn Welch. Trade liberalization and growth: new evidence. The World Bank Economic Review. Vol. 22. No. 2 (2008). P. 187-231.

\section{References:}

1. Arnold C. Harberger. Economic Policy and Economic Growth. San Francisco: International Center for Economic Growth, 1985, 48 p.

2. Balassa B. (1978) Exports and economic growth: further evidence, Journal of Development Economics, 5. P. 181-189.

3. Ben-David D., Equalizing Exchange: Trade Liberalization and Income Convergence, Quarterly Journal of Economices. Vol. 108. No. 3 (Aug., 1993). P. 653-679.

4. Chami Batista J., Latin American export specialization in resource-based products: implications for growth. The Developing Economies. XLII-3 (September 2004). P. 337-370.

5. Darbinyan A, Ordyan A. Opening of the economy as the main prerequisite and means of effective international economic integration, Social-economic transformation during 10 years of independence in Armenia (Collection of scientific articles). Yerevan. 2002. 422 p. (in Armenian).

6. Daryll E. Ray. Trade liberalization would shut down two-thirds of EU's grain and oilseed production, published in MidAmerica Farmer Grower. Vol. 21. No. 48. November 28. 2003. Article Number 173.

7. De Long J., Summers L. Equipment Investment and Economic Growth. The Quarterly Journal of Economics. Vol. 106. No. 2 (May, 1991). P. 445-502.

8. Denison E. Accounting for United States Economic Growth 1929-1969. The Brookings Institution, Washington D. C. $1974.355 \mathrm{p}$.

9. Dollar D. and Kraay A., Trade, Growth, and Poverty. The Economic Journal. Vol. 114. No. 493. Features (Feb., 2004). P. F22-F49.

10. Faini R. Trade liberalization in a globalizing world (Università di Roma Tor Vergata, CEPR, IZA and CSLA), Annual World Bank Conference on Development Economics, Washington, D. C. May 3-4, 2004,38 p.

11. Gabrielyan A. The relationship between economic freedom and economic growth in South Caucasus, Armenia: Finance and economy. № 10 (124), october 2010. P. 38-41 (in Armenian).

12. Hagelstam J., Mercantillism Still Influences Practical Trade Policy at the End of the Twentieth Century // Journal of World Trade, 1991. P. 95-105.

13. Hausmann R., J. Hwang and D. Rodrik. 2006. "What You Export Matters». Working Paper. Center for International Development, Harvard University, $31 \mathrm{p}$.

14. Krugman P. The Myth of Asia's Miracle, Foreign Affairs, 1994. P. 62-78.

15. Krugman P., Obstfeld M. International Economics, 5-th edition., St. Peterburg, 2004, 832 p. (in Russian).

16. Krugman/Obstfeld, International Economics. 2003, Chapter 2: Labor Productivity and Comparative Advantage: The Riparian Model, 712 p.

17. Maksimov A. The economy of Taiwan: results and prospects of development, M., 1991, 208 p. (in Russian).

18. Manasyan H. Components of Armenia's economic growth, Armenia: Finance and economy, 2002. No. 11. P. 31 (in Armenian).

19. Markosyan A. Armenia on the way to market economy: achievements and upcoming issues, Armenia: Finance and economy. № 13, december 2009. P. 18-23 (in Armenian).

20. McKinsey. "Armenia 2020». Yerevan 2005, 232 p.

21. Pebro M. International economic, financial and monetary relations, translation from French, 1994. 496 p. (in Russian).

22. Prebish R. The Economic Development of Latin America and its Principal Problems, United Nations Department of Economic Affairs. 1950. 247 p.

23. Reich R. The Work of Nations: Preparing Ourselves for 21st Century Capitalism, New-York: Vintage Books, 1991, $331 \mathrm{p}$.

24. Rizal Damuri Y., Atje R., Gaduh Arya B. Integration and Trade Specialization in East Asia, CSIS working paper series, March 2006, 42np.

25. Romer P. Endogenous technological change, Journal of Political Economy, 1990. P. 71-102.

26. Sangho K., Hyunjoon L. and Donghyun P. The Effect of Imports and Exports on Total Factor Productivity in Korea, 2002, 40 p.

27. Sarinyan R. Modern Armenian Theory of Economics, Yerevan, 2003, 232 p.

28. Shumilov W. International economic law, Book 2, 2-nd edition, M. 2001, 288 p. (in Russian).

29. Singer H. The Distribution of Trade between Investing and Borrowing Countries, American Economic Review, 1950. P. 473-485.

30. Torosyan T. Improvement of export and import ratio in Armenia, Economics: № 1-3. Yerevan, 1998. P. 4 (in Armenian).

31. Wacziarg R. and K.Horn Welch. Trade liberalization and growth: new evidence, The World Bank Economic Review. Vol. 22. No. 2 (2008). P. 187-231.

32. Yeritsyan N. Without high ambition, high results cannot be achieved Armenia: Finance and Economy. № 13, December 2009. P. 10-15 (in Armenian). 